\title{
Bigger is bigger. Better is better
}

\author{
Ole Solheim • Johan Cappelen
}

Received: 18 March 2011 / Accepted: 8 April 2011 /Published online: 4 May 2011

(C) The Author(s) 2011. This article is published with open access at Springerlink.com

Dear editor,

First, we would like to thank the editorial board for the interest in our study and the thorough and extensive commentary [18] to our publication, "The impact of provider surgical volumes on survival in children with primary tumours of the central nervous system - a population-based study" [48]. The editorial includes comments on central publications and addresses some of the problems with the available evidence concerning the volume-outcome relationship. We appreciate the opportunity to comment further on the argumentation for and against centralization of paediatric neurosurgery. If a surgeon does not practice surgery, he or she will not master the procedures. This is self-evident. This is why training and licensing is required to become specialists and subspecialists. Although, accepting a volume-outcome relationship, there are still many unanswered questions as to what to gain from centralisation of different neurosurgical procedures. Here, we would like to expand the literary review in the editorial and comment on the specific points in respect to our study.

The magnitude and importance of the volume-outcome relationship is difficult to assess from a review of the available literature. Major limitations rise from the fact that the data source are mainly American administrative claims databases or discharge summaries of variable quality that do not contain much clinical data. Usually, such record data

\section{O. Solheim $(\bowtie)$}

Department of Neuroscience,

Norwegian University of Science and Technology,

7005 Trondheim, Norway

e-mail: ole.solheim@ntnu.no

O. Solheim $\cdot$ J. Cappelen

Department of Neurosurgery, St.Olavs University Hospital,

Olav Kyrres gate,

7005 Trondheim, Norway only allow for crude adjustments for age, sex, ethnicity, hospital size and socioeconomic status [often just assessed as mean income in the postal code of the patient's residential address (!)]. The severity and incidence of the treated disease is not corrected for, and there are often considerable limitations in data concerning differences in referral and case mix [28, 29]. It should further be remembered that high volume institutions in the USA more often treat younger patients, whites, patients with private insurance and residents of wealthier areas. Hospitals with the highest volumes typically also have more elective cases.

In publications based on American administrative databases, the main outcome is usually surgical mortality, measured as in-house-mortality. Although 30-day mortality has a better face validity, the correlation to in-house mortality rates are generally at least moderate (kappa $>0.40$ ), but with variance across conditions [14]. Surgical mortality has in the USA been endorsed as an Inpatient Quality Indicator (IQI) by the Agency for Healthcare Research and Quality in eight surgical procedures for adults, including craniotomies (the other seven are specific surgical procedures, while craniotomy is the opening of a body part). The line of logic is that since (1) surgical mortality in craniotomies is defined as a quality indicator, and (2) surgical mortality in many publications is lower in high-volume providers of care, then (3) surgical volume is a quality indicator (quod erat demonstrandum). However, studies by the Veterans Affair (VA) National Surgical Quality Improvement Program (NSQIP), which prospectively collects clinical data on all major surgical operations in the VA, do not reach the same conclusions as studies based on administrative claims data: "Unlike retrospective studies that are based on administrative databases, NSQIP studies have failed to demonstrate a direct relationship between volume and risk-adjusted outcomes of surgery across various specialties. These studies have empha- 
sized that the quality of systems of care was more important than volume in determining the overall quality of surgical care at an institution. High-volume hospitals could still deliver poor care in as much as low-volume hospitals could deliver good care. NSQIP studies have also underscored the major limitations of claims data and administrative databases in the provision of adequate risk-adjustment models that are crucial for volume-outcome studies" [35].

\section{What is known about the volume-outcome relationship in neurosurgical tumour operations?}

There are ten publications that specifically address the effect of provider volume in various neurosurgical tumour operations [3, 5-7, 22, 25, 26, 38, 45, 48], nine of which are North American, and six of them involve the same author. As far as we are aware, there are only two publications, including ours, that assess long-term survival in relation to provider volumes [26, 48]. The Canadian study from Ontario 1977-1987 [26] and our study [48] reached opposite conclusions. Since surgical mortality is the main outcome parameter of the American studies, it would be of interest to know if perioperative mortality is indicative of overall treatment results. The overall prognosis of the disease is likely a strong predictor, since the 30-day mortality rate is merely the intonation of the Kaplan-Meier curve. This is presumably why simple biopsies are associated with a higher incidence of perioperative death than craniotomies [36]. The patient selection is likely crucial for such early outcomes, as severe adverse events leading to early death due to the surgical handiwork itself are exceedingly rare. In some publications, the observed difference has been between academic centres (teaching hospitals) and smaller non-academic centres [26, 38], while in others the teaching status of the hospitals was not specified. However, in many countries (including Norway), neurosurgery is not performed outside university hospitals.

Higher-volume providers are in one study reported to have superior short-term outcomes after surgical resection of malignant intracranial tumours. Surgical mortality for very low-volume to very high-volume hospitals were as follows: $3.8,3.2,2.4$, and $1.8 \%$. The numeric thresholds for hospital volumes were 1-84 cases per year (very low), 85147 cases per year (low), 148-292 cases per year (high), and more than 292 cases per year (very high). For surgeon volume, the thresholds were 1-6 cases per year (very low), 7-11 cases per year (low), 12-21 cases per year (high), and more than 21 cases per year (very high) [22]. US data from the Nationwide Inpatient Sample (NIS) suggested that higher-volume hospitals and surgeons provide superior short-term outcomes after transsphenoidal pituitary tumour surgery with shorter lengths of stay [7]. However, $64 \%$ of the hospitals treated only $1-4$ cases annually and $55 \%$ of surgeons treated only one patient annually. The median annual case load per surgeon in the US data was only three admissions. For acoustic neurinomas, higher-volume hospitals and higher volume surgeons were associated with superior short-term outcomes with shorter lengths of stay, however at no significant difference in perioperative mortality rates [5]. The surgical mortality and adverse hospital discharge rates were reported to be lower when meningioma surgery was performed by high-volume providers [25]. However, $51 \%$ of the treating hospitals only operated on one to three meningiomas annually and $48 \%$ of the surgeons in the study only operated on one meningioma per year. In metastatic brain tumours, it was also found that higher-volume hospitals and surgeons provided superior short-term outcomes, with shorter lengths of stay and a trend towards lower charges [3]. However, $41 \%$ of the hospitals operated on only one to two metastatic brain tumours per year and $50 \%$ of the surgeons operated on only one metastatic tumour annually. Perioperative mortality was lower when craniotomies in children were performed at high-volume hospitals and by high-volume surgeons in the United States, from 1988 to 2000 [45]. However, $68 \%$ of the hospitals treated only one to four paediatric brain tumours annually and $66 \%$ of the surgeons operated on only one paediatric case per year. Thus, low-volume institutions in the USA have much lower volumes than Norwegian and probably most European centres. The relevance of these findings to countries where healthcare is organized differently and where caseloads are higher remains unclear.

\section{What about other neurosurgical procedures?}

In the USA, complications after microvascular decompression (the Jeanetta procedure) were less frequent after surgery performed at high-volume hospitals or by high-volume surgeons. However, surgical volumes and mortality rates were not significantly related [33]. Sixty-eight percent of the American hospitals studied treated only one to two patients annually. American high-volume hospitals also had superior short-term outcomes in surgical treatment of Parkinson disease (both thalamotomies and deep-brain stimulation) [27].

In a US study of patients with unruptured aneurysms treated from 1996 to 2000, treatment at high-volume institutions or by high volume physicians was associated with significantly lower morbidity rates and modestly lower mortality rates $[4,31]$. However, in $64 \%$ of the hospitals, the annual volume of clipped elective aneurysms was only one to three cases. Another study reports that US patients with a diagnosis of subarachnoid haemorrhage (SAH) on the discharge records, who initially presented through the emergency department of a hospital with a high volume of 
SAH cases, had significantly lower mortality rates [24]. In California, hospitals that treated more patients with SAH had substantially lower rates of in-hospital mortality [2]. In New York, hospitals that frequently perform aneurysm operations had lower mortality rates for patients undergoing craniotomy for cerebral aneurysm than hospitals that performed fewer operations [8, 49]. It has also been reported that very-low-volume hospitals in the USA are associated with higher mortality rates than very-highvolume hospitals for both emergency and elective aneurysm surgery [23]. A study from California and New York suggested that mortality rates in older patients who are treated surgically for SAH may be inversely correlated with the annual number of craniotomies performed for SAH in patients 65 years of age or older at a given institution [50]. An American single-institution study in unruptured aneurysms also found that the surgeon's experience was a predictor of functional outcome [19]. Conversely, Japanese and English studies, and one American study [32] about surgical volumes in SAH found no mortality difference after correcting for confounders [30, 42, 52]. Despite different degrees of centralization and healthcare organisation, the outcome after SAH does not seem to differ from country to country [37].

A relationship between surgeon experience and shunt complications was seen in some studies $[13,20,41]$ but not in others $[34,43]$. In the USA, paediatric shunt procedures performed at high-volume hospitals or by high-volume surgeons were associated with lower inhospital mortality rates [46]. Some have speculated that the arrival of new interns and residents at teaching hospitals each July might cause an annual transient increase in poor patient outcomes and inefficient care. There was, however, no evidence that brain tumour or shunt surgery performed in paediatric patients at US teaching hospitals during July and August is associated with more frequent adverse patient outcome or inefficient care than similar surgery performed during other months [47]. It, therefore, seems unclear if hydrocephalus (the by far most prevalent condition in paediatric neurosurgery) will profit on centralized care.

\section{What is low?}

The nature of the learning curve in surgery is not fully understood. It is so far unclear whether the relationship between volume and outcome is continuous, step-wise, or has a single clear cut-off [17]. Therefore, the necessary degree of centralization to obtain a potential or optimal benefit is not known; being either local, regional, national, or even international. The definitions of high-volume and low-volume are relative. As seen in the review of the available literature, the provider volumes of the low-volume centres are often extremely low, at least by Norwegian standards.

\section{Surgeon volume or hospital volume?}

Institutional volumes are not necessarily related to the caseload of the individual surgeons. Larger institutional volumes do not only attract more difficult cases, but also proportionally as many easy operations, out-patient consultations and non-surgical work. To deal with the higher workload, there are naturally more physicians. Often the staff-to-patient ratio may be higher in larger institutions. The number of hours in the operating room (OR) per week per surgeon is, therefore, presumably not higher in highvolume institutions. The volume of difficult cases per surgeon depends much on the organization, thus the ability to choose the right surgeon for the right job (i.e. the system of care). It is our belief that it is possible to achieve high volumes of difficult procedures (with transferable) skills for selected surgeons also in smaller centres.

The focus in debates about centralization is usually institutional volumes. For many procedures, the observed associations between hospital volume and operative mortality is no longer found if adjusting for surgeons volumes [12]. But even among high-volume surgeons there may be significant differences in patient outcome $[9,10]$. As also acknowledged by the editorial, there are differences between surgeons with respect to talent. Both talent and professional interests may relate much to the final skills of the surgeon. Surgeons with academic positions are therefore not necessarily inferior, even though they may spend less time in the OR. Further, the systems care outside the OR, and the ability to follow guidelines and evidence-based practice of care and patient selection may play an important role for the final outcome. A department's ability to select the right personnel for the right job is depending on leadership and organization, and likely not institutional volume.

\section{What about clinical experience?}

Years of clinical experience has presumably a positive effect, if to believe in a simple volume-outcome relationship. Nevertheless, it has been seen that for some complex procedures, older surgeons have higher operative mortality rates than their younger colleagues [51]. A systematic review on the importance of medical knowledge and healthcare quality to years in practice and physician age concluded that "physicians who have been in practice longer may be at risk for providing lower-quality care" [16]. Although, many are ready to centralize surgical 
procedures based on the available low evidence data (with many outliers), few are ready to degrade experienced surgeons because of a similar statistical relationship. We believe such findings nevertheless further emphasize the importance of selecting the right physician for the right job, regardless of age and case volume.

\section{What is the cost-benefit of centralization?}

For neurosurgical procedures, this is not known. A populationbased study of 243,000 patients who underwent abdominal aortic aneurysm surgery, cororary by-pass surgery or coronary angioplasty in California compared different regionalization strategies. The authors concluded that "selective referral to high volume centers may, at best, yield only modest improvement in outcomes but would result in massive disruption in hospital services in California, and possibly in other decentralized health care environments. Selective avoidance of low volume hospitals would not lead to any improvement in outcomes... The use of procedure volume as the basis for evidence-based hospital referrals should be re-evaluated by all stake-holders before undertaking further efforts to regionalize healthcare delivery using volume-based referral strategies" [28]. The cost-benefit of centralization depends on the type of procedure, on how healthcare is organized, and the geographical and organizational challenges involved. A benefit of centralization of paediatric neurosurgery is questionable due to scarce and conflicting evidence. At the present, centralization in Norway would also possibly yield negative consequences in terms of survival for some patients [48]. For complex treatments that require extensive multidisciplinary and designated teams (such as certain types of craniofacial and epilepsy surgery) or special and expensive equipment (such as a stereotactic radiosurgery), the benefits of centralization are much easier to perceive.

Centralization of (all) paediatric neurosurgical procedures, as suggested by the editorial would have a major expense in terms of costs due to patient logistics and transportation (the distance from the northernmost part of Norway to Oslo is close to $2,000 \mathrm{~km}$ ). Centralization would also increase the social burden of disease by separating parents, siblings and patients from their local environment to receive routine check-ups, in times of crisis or during long-lasting treatments. Also to be remembered, complications are quite frequent after discharge following various neurosurgical procedures. This may be especially important in paediatric neurosurgery as, for instance, hydrocephalus, infratentorial surgery or myelomeningoceles are associated with a certain frequency of cerebrospinal fluid leaks, shunt malfunction or infections. Complications are best handled by the operating surgeon, who has all the information and knowledge about the very patient, and who feels personal responsibility for the outcome. Even today (without much centralisation), such neurosurgical patients may be admitted to general medical or surgical wards in their local hospitals, if distance to the neurosurgical department is too long. Here, their condition and their symptoms may frequently be misinterpreted. Our experience is that longer delays in treatment and more nihilistic approaches are seen if patients are not under the direct care of the responsible neurosurgeon. The mentioned side-effects of centralization may naturally be fewer in smaller and more densely populated countries. We agree with the editorial that "other outcomes, such as quality of life, may well be more important in this debate than mortality", but we find it unlikely that separation of families, longer distances, longer chains of referral and probably longer doctors' delays will effect quality of life positively.

\section{Is paediatric neurosurgery special?}

Based on the available evidence, it is hard to understand why paediatric neurosurgery is singled out as a field that likely will profit from centralization. Based on the scarce evidence available, just as strong (or stronger) arguments may be used for (most) other neurosurgical (and even medical) entities. There are many rare entities in most fields of neurosurgery, and paediatric brain tumours are not special in this respect. Although a fairly small speciality in number of surgeons, neurosurgery is a very diverse speciality involved in a wide range of different procedures. This is different from many other surgical specialities that are dominated by a few, frequent, and quite standardized procedures (e.g. coronary bypass surgery, hip replacements, cholecystectomies, etc.). The learning curves of neurosurgical procedures are, therefore, probably more complex to assess, understand and predict. There are also few standardized neurosurgical procedures and treatment guidelines. Therefore, indications, approaches, techniques and preferred technical aids may vary much from surgeon to surgeon and from centre to centre. There are around 130 different subtypes of primary central nervous system tumours [40], often with large variations in location, size and involvement of adjacent neurovascular structures. Although the adult tumour population is somewhat different from the paediatric tumour population (as pointed out in the editorial), most of the time a neurosurgeon has to rely on transferable skills, since the likelihood of operating the exact same entity with the exact same shape and location may be slim in many cases.

\section{Is surgery special?}

Many believe that, due to its practical nature, surgery is special in respect to the volume-outcome relationship. Both volume and outcome may be easier to measure in surgery, 
but seeming volume-outcome relationships have been observed in a broad range of medical settings, including sepsis treatment [15], testicular cancer [21], pulmonary embolism [1], peptic ulcers [39] and ischaemic stroke [44], among others. Thus, the arguments for centralization in neurosurgery may be just as strong or weak for a range of non-surgical procedures.

\section{Is there enough evidence to support centralization?}

So far, this is unfortunately a question of faith; but the editors are clearly believers. Available evidence is scarce and frequently associated with major methodological flaws and confirmation bias. Based on the available evidence, it is impossible to quantify and foresee the effects of centralization, and the cost-benefit therefore remains a division of unknowns. What can then be learned? Although impractical to utilize on a national level, the evidence for centralization to certain surgeons seems higher than to certain institutions - as long as surgeons are not too old (!). The selection of the right surgeon for the right job is utterly important. This can be a focus in all neurosurgical centres, regardless of institutional volumes. It is not documented that paediatric neurosurgery is special in respect to potential benefits of centralization, but tolls for such patients and their families would likely be higher than in adults. A systematic review on the volume-outcomerelationship in cancer surgery concluded that most studies are not robust enough to support major policy decisions [11]. Another investigation on the methods of the available volume outcome research concluded that: "Volume offers an easy, simple measure that can be easily understood and employed by both healthcare providers and consumers. However, the use of volume as a quality indicator is not as straightforward as it may seem... In the meantime, it seems premature to be moving forward with referrals based on volume alone when there are still many issues to be resolved. We strongly support the profession, the consumers, and the purchasers of healthcare for their desire to truly understand high quality health care, but we also caution against oversimplified solutions that do not accurately address those concerns" [17].

\section{Weaknesses in our study}

The editorial points at five specific weaknesses in our study. Some of them are already discussed in the paper.

1. The low number of operations in Norway (risk of type II statistical error): as acknowledged in the paper, this potential power problem is not solvable, as the paper included all operated tumours. However, the potential power problem is not a concern for the subgroup where a statistical difference was observed [primitive neuroectodermal tumours (PNETs)/medulloblastomas]. The editorial also speculates if surgeon volumes were small at even the largest centre. To be remembered, the study included only first time operations for central nervous system tumours, and the numbers do not reflect the total number of craniotomies. As already mentioned, there is no agreement on what is small and what is not. Our findings may not necessarily apply to centres where volumes are different, training is less uniform or healthcare is differently organized.

2. There were statistical imbalances in the distribution of some tumour entities, in particular choroid plexus tumours. As acknowledged in our paper, we cannot explain this finding, but lack of a central histopathological review (which is unrealistic in studies of this magnitude) may allow for some differences in classification. There may also be differences in reporting. As choroid plexus tumours are most frequently benign, the higher percentage operated in the larger centre, would unlikely alter the results in favour of the higher volume centre.

3. One hundred and twenty-seven patients were excluded, as they harboured lesions which were not histologically confirmed. The editorial asks for a better description of these patients. This is likely a heterogenous group ranging from benign, subclinical lesions like Rathke's cleft cycts and incidental dysembryoplastic neuroepithelial tumours (DNETs) to highly malignant pons gliomas. (Biopsies of mid brain gliomas have not routinely been carried out in Norway). There was no significant difference in survival between geographical health regions for this heterogenous group of 127 patients: 78\% 5-year survival (low-volume regions) vs 66\% 5-year survival (high-volume region) $(p=0.31)$. Thus, a potential selection bias in relation to this group does not alter the conclusion of our paper. The study only included tumours that were histologically confirmed. When histopathology was available at a later stage (e.g. after a wait-and-can approach), survival was measured from date of surgery. Tumours that were only histologically confirmed post-mortem were not included in our analyses (three cases).

4. The editors speculate that some of the difference attributable to variations between centres in respect to PNETs/medulloblastomas may be due to differences in the management of relapse. This may be one of several possible explanations. However, we have no information on how relapsing disease was treated in the different 
regions. Regardless of cause, we find the difference in survival disturbing.

5. Insufficient information was given regarding "set-up" of paediatric neurosurgery in Norway. A national review on individual caseloads of Norwegian neurosurgeons found the caseload of tumours per surgeon to be quite similar across centres (despite differences in institutional volumes). In the high-volume centre, there is a separate bed ward for paediatric surgery, served by a team of designated paediatric neurosurgeons. In the other centres, paediatric neurosurgery is handled by one or two responsible surgeons that for the most part serve adults.

\section{Conflicts of interest None.}

Open Access This article is distributed under the terms of the Creative Commons Attribution Noncommercial License which permits any noncommercial use, distribution, and reproduction in any medium, provided the original author(s) and source are credited.

\section{References}

1. Aujesky D, Mor MK, Geng M, Fine MJ, Renaud B, Ibrahim SA (2008) Hospital volume and patient outcomes in pulmonary embolism. CMAJ 178:27-33

2. Bardach NS, Zhao S, Gress DR, Lawton MT, Johnston SC (2002) Association between subarachnoid hemorrhage outcomes and number of cases treated at California hospitals. Stroke 33:1851-1856

3. Barker FG 2nd (2004) Craniotomy for the resection of metastatic brain tumors in the U.S., 1988-2000: decreasing mortality and the effect of provider caseload. Cancer 100:999-1007

4. Barker FG 2nd, Amin-Hanjani S, Butler WE, Ogilvy CS, Carter BS (2003) In-hospital mortality and morbidity after surgical treatment of unruptured intracranial aneurysms in the United States, 1996-2000: the effect of hospital and surgeon volume. Neurosurgery 52:995-1007, discussion 1007-1009

5. Barker FG 2nd, Carter BS, Ojemann RG, Jyung RW, Poe DS, McKenna MJ (2003) Surgical excision of acoustic neuroma: patient outcome and provider caseload. Laryngoscope 113:1332-1343

6. Barker FG 2nd, Curry WT Jr, Carter BS (2005) Surgery for primary supratentorial brain tumors in the United States, 1988 to 2000: the effect of provider caseload and centralization of care. Neuro Oncol 7:49-63

7. Barker FG 2nd, Klibanski A, Swearingen B (2003) Transsphenoidal surgery for pituitary tumors in the United States, 1996-2000: mortality, morbidity, and the effects of hospital and surgeon volume. J Clin Endocrinol Metab 88:4709-4719

8. Berman MF, Solomon RA, Mayer SA, Johnston SC, Yung PP (2003) Impact of hospital-related factors on outcome after treatment of cerebral aneurysms. Stroke 34:2200-2207

9. Bianco FJ Jr, Riedel ER, Begg CB, Kattan MW, Scardino PT (2005) Variations among high volume surgeons in the rate of complications after radical prostatectomy: further evidence that technique matters. J Urol 173:2099-2103

10. Bianco FJ, Jr., Vickers AJ, Cronin AM, Klein EA, Eastham JA, Pontes JE, Scardino PT Variations among experienced surgeons in cancer control after open radical prostatectomy. J Urol 183:977-982
11. Bilimoria KY, Phillips JD, Rock CE, Hayman A, Prystowsky JB, Bentrem DJ (2009) Effect of surgeon training, specialization, and experience on outcomes for cancer surgery: a systematic review of the literature. Ann Surg Oncol 16:1799-1808

12. Birkmeyer JD, Stukel TA, Siewers AE, Goodney PP, Wennberg DE, Lucas FL (2003) Surgeon volume and operative mortality in the United States. N Engl J Med 349:2117-2127

13. Borgbjerg BM, Gjerris F, Albeck MJ, Borgesen SE (1995) Risk of infection after cerebrospinal fluid shunt: an analysis of 884 firsttime shunts. Acta Neurochir (Wien) 136:1-7

14. Borzecki AM, Christiansen CL, Chew P, Loveland S, Rosen AK (2010) Comparison of in-hospital versus 30-day mortality assessments for selected medical conditions. Med Care 48:1117-1121

15. Chen CH, Chen YH, Lin HC, Lin HC (2009) Association between physician caseload and patient outcome for sepsis treatment. Infect Control Hosp Epidemiol 30:556-562

16. Choudhry NK, Fletcher RH, Soumerai SB (2005) Systematic review: the relationship between clinical experience and quality of health care. Ann Intern Med 142:260-273

17. Christian CK, Gustafson ML, Betensky RA, Daley J, Zinner MJ (2005) The volume-outcome relationship: don't believe everything you see. World J Surg 29:1241-1244

18. Chumas P, Kenny T, Stiller C (2011) Subspecialisation in neurosurgery-does size matter? Acta Neurochir (Wien). doi:10.1007/s00701-011-0970-0

19. Chyatte D, Porterfield R (2001) Functional outcome after repair of unruptured intracranial aneurysms. J Neurosurg 94:417-421

20. Cochrane DD, Kestle JR (2003) The influence of surgical operative experience on the duration of first ventriculoperitoneal shunt function and infection. Pediatr Neurosurg 38:295-301

21. Collette L, Sylvester RJ, Stenning SP, Fossa SD, Mead GM, de Wit R, de Mulder PH, Neymark N, Lallemand E, Kaye SB (1999) Impact of the treating institution on survival of patients with "poor-prognosis" metastatic nonseminoma. European Organization for Research and Treatment of Cancer Genito-Urinary Tract Cancer Collaborative Group and the Medical Research Council Testicular Cancer Working Party. J Natl Cancer Inst 91:839-846

22. Cowan JA Jr, Dimick JB, Leveque JC, Thompson BG, Upchurch GR Jr, Hoff JT (2003) The impact of provider volume on mortality after intracranial tumor resection. Neurosurgery 52:4853, discussion 53-44

23. Cowan JA Jr, Dimick JB, Wainess RM, Upchurch GR Jr, Thompson BG (2003) Outcomes after cerebral aneurysm clip occlusion in the United States: the need for evidence-based hospital referral. J Neurosurg 99:947-952

24. Cross DT 3rd, Tirschwell DL, Clark MA, Tuden D, Derdeyn CP, Moran CJ, Dacey RG Jr (2003) Mortality rates after subarachnoid hemorrhage: variations according to hospital case volume in 18 states. J Neurosurg 99:810-817

25. Curry WT, McDermott MW, Carter BS, Barker FG 2nd (2005) Craniotomy for meningioma in the United States between 1988 and 2000: decreasing rate of mortality and the effect of provider caseload. J Neurosurg 102:977-986

26. Danjoux CE, Jenkin RD, McLaughlin J, Grimard L, Gaspar LE, Dar AR, Fisher B, Whitton AC, Kraus V, Springer CD et al (1996) Childhood medulloblastoma in Ontario, 1977-1987: populationbased results. Med Pediatr Oncol 26:1-9

27. Eskandar EN, Flaherty A, Cosgrove GR, Shinobu LA, Barker FG 2nd (2003) Surgery for Parkinson disease in the United States, 1996 to 2000: practice patterns, short-term outcomes, and hospital charges in a nationwide sample. J Neurosurg 99:863-871

28. Glance LG, Osler TM, Mukamel DB, Dick AW (2008) Impact of the present-on-admission indicator on hospital quality measurement: experience with the Agency for Healthcare Research and Quality (AHRQ) Inpatient Quality Indicators. Med Care 46:112-119 
29. Halm EA, Lee C, Chassin MR (2002) Is volume related to outcome in health care? A systematic review and methodologic critique of the literature. Ann Intern Med 137:511-520

30. Hattori N, Katayama Y, Abe T (2007) Case volume does not correlate with outcome after cerebral aneurysm clipping: a nationwide study in Japan. Neurol Med Chir (Tokyo) 47:95100, discussion 100-101

31. Hoh BL, Rabinov JD, Pryor JC, Carter BS, Barker FG 2nd (2003) In-hospital morbidity and mortality after endovascular treatment of unruptured intracranial aneurysms in the United States, 19962000: effect of hospital and physician volume. AJNR Am J Neuroradiol 24:1409-1420

32. Johnston SC (2000) Effect of endovascular services and hospital volume on cerebral aneurysm treatment outcomes. Stroke 31:111-117

33. Kalkanis SN, Eskandar EN, Carter BS, Barker FG 2nd (2003) Microvascular decompression surgery in the United States, 1996 to 2000: mortality rates, morbidity rates, and the effects of hospital and surgeon volumes. Neurosurgery 52:1251-1261, discussion 1261-1252

34. Kestle J, Milner R, Drake J (1999) The shunt design trial: variation in surgical experience did not influence shunt survival. Pediatr Neurosurg 30:283-287

35. Khuri SF, Henderson WG (2005) The case against volume as a measure of quality of surgical care. World J Surg 29:1222-1229

36. Lassen B, Helseth E, Ronning P, Scheie D, Johannesen TB, Maehlen J, Langmoen IA, Meling TR Surgical mortality at 30days and complications leading to recraniotomy in 2630 consecutive craniotomies for intracranial tumors. Neurosurgery

37. Lipsman N, Tolentino J, Macdonald RL (2009) Effect of country or continent of treatment on outcome after aneurysmal subarachnoid hemorrhage. Clinical article. J Neurosurg 111:67-74

38. Long DM, Gordon T, Bowman H, Etzel A, Burleyson G, Betchen S, Garonzik IM, Brem H (2003) Outcome and cost of craniotomy performed to treat tumors in regional academic referral centers. Neurosurgery 52:1056-1063, discussion 1063-1055

39. Lou HY, Lin HC, Chen KY (2008) Hospital case volume and clinical outcomes for peptic ulcer treatment. J Gen Intern Med 23:1693-1697

40. Louis DN, Ohgaki H, Wiestler OD, Cavenee WK, Burger PC, Jouvet A, Scheithauer BW, Kleihues P (2007) The 2007 WHO classification of tumours of the central nervous system. Acta Neuropathol 114:97-109

41. Lund-Johansen M, Svendsen F, Wester K (1994) Shunt failures and complications in adults as related to shunt type, diagnosis, and the experience of the surgeon. Neurosurgery 35:839-844, discussion 844

42. Mitchell P, Gregson BA, Hope T, Mendelow AD (2005) Regional differences in outcome from subarachnoid haemorrhage. Acta Neurochir (Wien) 147:959-964, discussion 964

43. Piatt JH Jr, Carlson CV (1993) A search for determinants of cerebrospinal fluid shunt survival: retrospective analysis of a 14-year institutional experience. Pediatr Neurosurg 19:233-241, discussion 242

44. Saposnik G, Baibergenova A, O'Donnell M, Hill MD, Kapral MK, Hachinski V (2007) Hospital volume and stroke outcome: does it matter? Neurology 69:1142-1151

45. Smith ER, Butler WE, Barker FG 2nd (2004) Craniotomy for resection of pediatric brain tumors in the United States, 1988 to 2000: effects of provider caseloads and progressive centralization and specialization of care. Neurosurgery 54:553-563, discussion 563-555

46. Smith ER, Butler WE, Barker FG 2nd (2004) In-hospital mortality rates after ventriculoperitoneal shunt procedures in the United States, 1998 to 2000: relation to hospital and surgeon volume of care. J Neurosurg 100:90-97

47. Smith ER, Butler WE, Barker FG 2nd (2006) Is there a "July phenomenon" in pediatric neurosurgery at teaching hospitals? $\mathrm{J}$ Neurosurg 105:169-176

48. Solheim O, Salvesen Ø, Cappelen J, Johannesen TB (2011) The impact of provider surgical volumes on survival in children with primary tumors of the central nervous system - a population-based study. Acta Neurochir (Wien). doi:10.1007/s00701-011-0967-8

49. Solomon RA, Mayer SA, Tarmey JJ (1996) Relationship between the volume of craniotomies for cerebral aneurysm performed at New York state hospitals and in-hospital mortality. Stroke 27:13-17

50. Taylor CL, Yuan Z, Selman WR, Ratcheson RA, Rimm AA (1997) Mortality rates, hospital length of stay, and the cost of treating subarachnoid hemorrhage in older patients: institutional and geographical differences. J Neurosurg 86:583-588

51. Waljee JF, Greenfield LJ, Dimick JB, Birkmeyer JD (2006) Surgeon age and operative mortality in the United States. Ann Surg 244:353-362

52. Yasunaga H, Matsuyama Y, Ohe K (2008) Risk-adjusted analyses of the effects of hospital and surgeon volumes on postoperative complications and the modified Rankin scale after clipping of unruptured intracranial aneurysms in Japan. Neurol Med Chir (Tokyo) 48:531-538, discussion 538 